\title{
The Enormity of Chronic Kidney Disease in Nigeria: The Situation in a Teaching Hospital in South-East Nigeria
}

\author{
Ifeoma I. Ulasi and Chinwuba K. Ijoma \\ Renal Unit, Department of Medicine, College of Medicine, UNTH, Enugu 400001, Nigeria \\ Correspondence should be addressed to Ifeoma I. Ulasi, ifeomaulasi@yahoo.co.uk \\ Received 16 November 2009; Revised 1 February 2010; Accepted 4 March 2010 \\ Academic Editor: Marcel Tanner
}

Copyright (c) 2010 I. I. Ulasi and C. K. Ijoma. This is an open access article distributed under the Creative Commons Attribution License, which permits unrestricted use, distribution, and reproduction in any medium, provided the original work is properly cited.

\begin{abstract}
Background. The magnitude of the problem of chronic kidney disease (CKD) is enormous, and the prevalence keeps rising. To highlight the burden of CKD in developing countries, the authors looked at end-stage renal disease (ESRD) patients seen at the University of Nigeria Teaching Hospital (UNTH), Enugu, South-East Nigeria. Method. ESRD patients seen from 01/05/1990 to 31/12/2003 were recruited. Records from A\&E Department, medical-out-patients, wards and dialysis unit were used. Results. A total of 1001 male versus 537 female patients were reviewed. About 593 male versus 315 female patients had haemodialysis. The mean age was $42.55 \pm 15.43$ years and $86.5 \%$ were $<60$ years. Primary renal disease could not be determined in $51.6 \%$ while hypertension and glomerulonephritis accounted for $-17.2 \%$ and $14.6 \%$, respectively. Death from renal causes constituted $22.03 \%$ of medical deaths. Conclusion. The prognosis for CKD patients in Nigeria is abysmal. Only few patients had renal-replacementtherapy (RRT). The prohibitive cost precludes many patients. This underscores the need for preventive measures to reduce the impact of CKD in the society.
\end{abstract}

\section{Introduction}

The magnitude of the problem of chronic kidney disease (CKD) is enormous, and the prevalence of kidney failure is rising. Currently, CKD is emerging as a worldwide public health problem. The World Health Report 2002 and Global Burden of Disease project reports show that diseases of the kidney and urinary tract contribute to the global burden of diseases-with approximately 850,000 deaths every year and 15,010,167 disability-adjusted life years. Globally, they represent the 12th cause of death and 17th cause of disability [1]. This may however be an underrepresentation of the contribution of CKD to global burden of disease.

Apart from the effect on kidney function per se, kidney damage is a major determinant for the development of progression of accelerated atherosclerosis, ischaemic vascular disease, and cardiovascular death [2]. Individuals with even the earliest signs of CKD are at increased risk of cardiovascular disease and may die long before they reach end-stage renal disease. The burden of CKD is therefore not limited to its impact on demand of renal replacement therapy
(RRT); it is paralleled by the huge cost of provision of health care services for these patients. The cost of care includes not only the direct cost of dialysis and transplant services but also indirect cost like man hours lost at the workplace.

In Nigeria, the situation is such that CKD represents about $8-10 \%$ of hospital admission $[3,4]$. This may be a huge underrepresentation of the true situation. It is well known that CKD is underrecognized and underdiagnosed, patients with end-stage renal failure (ESRD) are thought to represent the tip of the iceberg of the entire burden of CKD $[5,6]$. This is more so in developing countries where patients often present late or not at all to health facilities for several reasons which range from prohibitive cost of health care services to use of alternative treatment like spiritual healing and traditional/native healers $[7,8]$.

The cost of management of ESRD is prohibitive [9]. In developing countries in places where RRT is available it is unaffordable by most patients. In Nigeria as in most other developing countries, there is no social security system or health insurance scheme in place to assist the patient, and the burden is borne solely by the patient and relatives. 
With this background, this study was carried out to highlight the plight of patients with ESRD in a typical developing country and to underscore the need for preventive measures, early detection, and intervention to stem the rising prevalence and to alleviate the burden of the disease.

\section{Method}

All consecutive patients with ESRD seen by the Renal Unit of the Department of Medicine University of Nigeria Teaching Hospital (UNTH), Enugu, South-East Nigeria from the inception of its Dialysis program in May 1990 to December 2003 (period of 13 years) were studied. The UNTH is a 760-bed hospital that serves about a third of the Nigerian population approximately 128 million (2005 estimate) [10]. Ethical clearance was obtained from the Ethics committee of the University of Nigeria Teaching Hospital. Patients' charts were reviewed after prior consent by the two authors together. Patients seen either in clinic or admitted with CKD were recruited but only patients with ESRD as defined by Kidney Disease Improving Global Outcome (KDIGO) were analyzed. ESRD patients with ambiguous records were excluded, as well as patients with acute on chronic renal failure or acute renal failure. Patients who had symptoms and signs of renal disease $\geq 3$ months, with glomerular filtration rate of $<15 \mathrm{ml} / \mathrm{min}$, imaging kidney sizes $<9 \mathrm{~cm}$ in length and who were on any form of renal replacement therapy were included. The determination of the primary cause of renal disease was based on history, physical examination, and laboratory investigations such as ultrasonography, urinalysis, blood chemistry, and serology. Histological documentation of primary renal disease was only possible in very few cases, some from kidney biopsy and some from postmortem studies. Chronic glomerulonephritis (CGN) diagnosis was largely clinical, based on classical symptoms of loin pain, haematuria, proteinuria, and reduced urine output and in a few on histological features of inflammation in the kidney on light microscopy. Unfortunately immunofluoresence and electron microscopy are not available in our centre. Split skin smear for acid fast bacilli is done for leprosy. Serology is available for Hep B, HCV, and HIV in our centre and Western blot confirmatory tests were done for those who screened HIV positive. HIV-associated nephropathy (HIVAN) was diagnosed if patient was confirmed HIV positive with low CD4 T cell count and had proteinuria, oedema, and normal-sized or enlarged kidneys on ultrasound. Light microscopy histology of HIVAN from kidney biopsy and from postmortem data was used in some patients. As a routine in the unit, all patients who have CKD are screened for HIV I and II after counseling. Hypertension was noted as cause of renal disease in some cases with log documented medical record if hypertension predated kidney disease and also absence of proteinuria, normal renal function indices, and preserved renal sizes in presence of hypertension early in the illness. Diabetic nephropathy (DN) was diagnosed if patient had a long history of DM and evidence of significant proteinuria as well as presence of other complications of DM for those with insulin-requiring DM. While for those with noninsulin-requiring DM, diagnosis was based on presence of significant proteinuria and presence of other complications of DM, and in very few from postmortem. Diagnosis of kidney disease from nephrotoxins was made by exclusion of known and common causes of CKD, a strong positive history of use of nephrotoxins (such as native medications, NSAIDs, etc.) and evidence of suggestive urine picture.

Patients were followed up from presentation at the Renal Clinic, Accident \& Emergency Department or through referral from other units or departments in the hospital. Records of all medical and renal cases admitted over the period were reviewed. Also records of deaths of medical and renal patients were collected. The total number of new cases seen in the clinic, the number admitted, and the patients who had any form of replacement therapy by way of haemodialysis or kidney transplantation were documented. The prevalent form of dialysis in the center has been haemodialysis because of problems of nonavailability of peritoneal dialysis fluids and repeated infections.

\section{Statistical Analysis}

The Statistical Package for Social Sciences (SSPS Inc, Chicago, IL) version 16 statistical software was used for data analysis. For continuous variables, mean values and standard deviations were calculated and the means were compared using ANOVA or two-sample $t$-test. Categorical variables were compared using the nonparametric tests-Chi-squares and Kruskal Wallis. The cross-tabulation was used to analyse the relationship between the stages of chronic kidney disease. All tests were two tailed with $P<.05$ taken as statistically significant.

\section{Results}

The flow of patients in the medical and renal outpatient departments, the medical wards, as well as the number of deaths from medical and renal causes during the study period are as shown in Table 1. Renal outpatient attendance represents $23.17 \%$ of all medical outpatient attendance. A total of 1538 patients with ESRD were admitted over the study period (1001 male and 537 female patients). Only 908 patients (593 male and 315 female patients) had haemodialysis, that is, $59.04 \%$ (20.48\% female and $38.56 \%$ male patients) accepted dialysis and could pay for it thus they were on HD. The remainder though in ESRD and needing RRT did not get dialysis because either they could not pay for $\mathrm{HD}$ or opted for pre-emptive transplant or did not give consent for HD.

ESRD cases accounted for $7.96 \%$ of all medical admissions and $41.69 \%$ of renal admissions. Deaths from renal disease constituted about $22.03 \%$ of all medical deaths on admission.

4.1. Age Distribution of Patients. The mean age of patients was $42.55 \pm 15.43$ years with males being $43.66 \pm 15.38$ years and the females younger $40.48 \pm 15.31$ years; the 
TABlE 1: Records of patients' outpatient attendance, admission/death by sex.

\begin{tabular}{lcc}
\hline & \multicolumn{2}{c}{ Number (\%) } \\
\hline Medical outpatient: & $19,661(54.5)$ & $16,436(45.5)$ \\
New cases & $85,322(48.3)$ & $91,254(51.7)$ \\
Old cases & & \\
\hline Renal Outpatient: & $6065(55.8)$ & $4813(44.3)$ \\
New cases & $32,218(46.7)$ & $36,766(53.3)$ \\
Old cases & $11430(59.2)$ & $7887(40.8)$ \\
Medical Admissions & $2229(60.4)$ & $1460(39.6)$ \\
Renal Admissions & $1001(65.1)$ & $537(34.9)$ \\
ESRD Admissions & $593(65.3)$ & $315(34.7)$ \\
Patients on dialysis & $3258(63.6)$ & $1862(36.4)$ \\
Medical Deaths & $746(66.1)$ & $382(33.9)$ \\
Renal Deaths &
\end{tabular}

ESRD: end-stage renal disease.

difference was significant statistically, $P<.001$. Most of the patients seen $(86.5 \%)$ were less than 60 years of age, Table 2 .

4.2. Primary Renal Disease. In most of the patients (51.6\%) the primary renal disease could not be determined; however in those whose primary renal disease was known hypertension was most prevalent $(17.2 \%)$, Table 2 . Of the 1538 patients reported in this study, 32 had confirmed HIV while 29 were documented to have HIVAN. This number constituted $13 \%$ of the patients with CGN. In 22 patients, history of ingestion of a nephrotoxic agent and urinalysis showing leucocyturia with eosinophilia among other findings were suggestive of nephrotoxic damage. Type II DM was noted in $147(80.8 \%)$ while 35 (19.2\%) had type I DM.

Postmortem (PM) was performed in about 49 patients over the period 1990 to 2003. Clinical suspicion was confirmed in about $50 \%$ of the PMs done. The histology of these cases revealed chronic glomerulonephritis-33\%, diabetic nephropathy-22\%, hypertension-18\%, and chronic pyelonephritis/chronic interstitial nephritis-11\%, and mixed picture of chronic pyelonephritis and diabetic nephropathy, chronic pyelonephritis and hypertensive nephrosclerosis or hypertensive nephrosclerosis, chronic pyelonephritis, and diabetic nephropathy were documented in $16 \%$.

4.3. Renal Replacement Therapy: Prevalence and Duration of Dialysis and Prevalence of Transplant. More than three quarters of the patients defaulted after five sessions of haemodialysis. Further analysis showed that a good number of patients discontinued dialysis after about three months of haemodialysis, Table 3(a). Reasons for withdrawal were mostly financial, a few were referred out to other centres because of distance from facility and for kidney transplantation (our centre does not offer transplant service), Table 3(b).
The mean session of dialysis was very low being $6.01 \pm$ 14.69 with a range of $1-398$ sessions. Fifty-eight patients, that is, $6.39 \%$ of dialysed patients had permanent access created for maintenance haemodialysis. Although only $6.39 \%$ of patients had permanent vascular access in the form of $\mathrm{A}-\mathrm{V}$ fistula and $\mathrm{A}-\mathrm{V}$ graft, the rest were dialyzed by temporary accesses including subclavian vein, internal jugular vein, and femoral vein cannulation. All patients in ESRD who accept maintenance $\mathrm{HD}$ as modality of definitive treatment get prescription for creation of permanent vascular access but majority are unable to afford the cost and few believe they may not need it if they would get kidney transplant in the long run.

Only 6 patients $(0.39 \%)$ had kidney transplantation.

\section{Discussion}

This study was undertaken to highlight the high prevalence of ESRD in developing countries such as Nigeria as well as to emphasize the abysmal outcome for such patients. Only a small fraction of patients admitted with ESRD had renal replacement therapy. Nigeria's health expenditure $(<\$ 4 /$ capita/year) is ranked among the lowest in the world [11]. The cost of management of ESRD is prohibitive all over the world. But unfortunately in Nigeria as in many other developing countries, the burden of cost of health services is borne solely by the patients and their relatives. The recently introduced National Health Insurance Scheme in Nigeria does not cover CKD patients. Furthermore, about $60 \%$ of Nigerians live below the poverty line [10] (world factbook). Financial constraint has been documented by various studies as a major impediment in renal replacement therapy in developing countries. In an analysis of cost implication of treatment of ESRD in Nigeria, Ijoma et al. [9] concluded that cost of treatment of ESRD was exorbitant and far beyond the reach of the average Nigerian. As noted by Wairaga [12] in Kenya, resource is scarce yet the ESRD patient load rises at alarming rate in Africa. Another article on ESRD in SubSaharan Africa showed an average increase of 75\% from 2000 to 2004 with a range of $35.2 \%$ to $150 \%$ in the countries represented in the survey [13].

Above data underscore the need for emphasis to be placed on preventive measures. Prevention can be primordial, primary, secondary, or tertiary and articulated at various tiers of government-national, state or province or region, local government area, division or council. Nongovernmental organizations can and have been used for such enlightenment campaigns to raise awareness in the communities. Community heads and the leadership of the community can also be utilized to raise awareness especially for those measures that can be carried out at the individual and community level such as lifestyle modification, personal, and environmental cleanliness. Other measures would include getting authorities and professional bodies to mount public enlightenment campaign to identify nephrotoxic agents and discourage their use and establishment of good primary health care policy by the government, with health centres accessible and affordable for patients. Measures as 
TABLE 2: Age group of patients by diseases.

\begin{tabular}{|c|c|c|c|c|}
\hline \multirow{2}{*}{ Primary renal disease } & \multicolumn{4}{|c|}{ Age groups number (\%) } \\
\hline & $12-35$ & $36-60$ & $\geq 61$ & Total \\
\hline Uncertain causes & $375(24.4)$ & $340(22.1)$ & $79(5.1)$ & $794(51.6)$ \\
\hline CGN & $149(9.7)$ & $67(4.35)$ & $10(0.65)$ & $226(14.8)$ \\
\hline Hypertension & $8(0.5)$ & $210(13.65)$ & $47(3.05)$ & $265(17.2)$ \\
\hline Diabetes Mellitus & $13(0.8)$ & $115(7.5)$ & $54(3.5)$ & $182(11.8)$ \\
\hline Others & $18(1.15)$ & $35(2.3)$ & $18(1.15)$ & $71(4.6)$ \\
\hline Total & $563(36.6)$ & $767(49.9)$ & $208(13.5)$ & $1538(100)$ \\
\hline
\end{tabular}

*Others sickle cell nephropathy—2 (2.8\%), ADPKD—5 (7.0\%), toxic nephropathy-22 (31.0\%), obstructive uropathy—20 (28.2\%), chronic pyelonephritis-22(31.0\%).

TABLe 3

(a) Duration of dialysis by number of sessions of dialysis.

\begin{tabular}{lccccc}
\hline $\begin{array}{l}\text { Duration } \\
\text { (months) }\end{array}$ & $1-5$ & $6-10$ & $11-49$ & $\geq 50$ & Total (\%) \\
\hline$<1$ & 694 & 18 & 3 & 0 & $715(78.7)$ \\
$1-3$ & 12 & 68 & 36 & 0 & $116(12.8)$ \\
$3-6$ & 0 & 1 & 36 & 0 & $37(4.1)$ \\
$6-9$ & 1 & 0 & 19 & 1 & $21(2.3)$ \\
$9-12$ & 0 & 0 & 5 & 0 & $5(0.5)$ \\
$12-24$ & 0 & 0 & 4 & 5 & $9(1.0)$ \\
$>24$ & 0 & 0 & 1 & 4 & $5(0.5)$ \\
\hline Total & $707(77.9)$ & $87(9.6)$ & $104(11.4)$ & $10(1.1)$ & $908(100)$ \\
\hline \multicolumn{7}{r}{}
\end{tabular}

(b) Reasons for withdrawal.

\begin{tabular}{lc}
\hline Reasons & $\%$ \\
\hline Financial & 91.5 \\
Distance from dialysis facility & 0.8 \\
Death & 3.7 \\
Referred out* & 1.2 \\
Withdrawal of consent & 0.1 \\
Others & 2.7 \\
\hline
\end{tabular}

${ }^{*}$ Others referred out for kidney transplantation.

regular evaluation in a health facilities and regular screening for communicable and noncommunicable diseases should be advocated. Early treatment of identified diseases and timely referral to nephrologists in established CKD.

Most patients in Nigeria present late to health facilities. Often times before presenting to a health facility they would have tried various forms of alternative treatment like spiritual healing and traditional/native healers mainly because of reasons related to accessibility and affordability of health care services $[7,8]$. Indeed, a large proportion of patients with chronic illnesses die without presenting to any health facility. In this present study, only a little over $50 \%$ of patients seen with ESRD who should have dialysis had it and only a very small fraction had near optimal dialysis. Majority of patients defaulted after few sessions of haemodialysis. Arije et al. [15] made similar observations in their study in South-West Nigeria. They noted that $70.8 \%$ of their
TABLE 4: Comparison of present study with data from a developed country.

\begin{tabular}{|c|c|c|}
\hline & Present study & $\begin{array}{l}\text { ANZData Registry } \\
{[14]}\end{array}$ \\
\hline Mean age (yrs) & 42.55 & 65 \\
\hline Peak age group & $36-60$ years & $65-74$ years \\
\hline Age prevalence & $86 \% \leq 60$ years & $45 \% \geq 65$ years \\
\hline Time of presentation & CKD stage $4 \& 5$ & $\begin{array}{l}25 \%<3 \text { months } \\
\text { prior to } 1 \text { st dialysis }\end{array}$ \\
\hline $\begin{array}{l}\% \text { with Permanent } \\
\text { access }\end{array}$ & 6.39 & $30-50$ \\
\hline Dialysis sessions & $\begin{array}{l}\text { Most had a total } \\
\text { number } \leq 10\end{array}$ & 3/week \\
\hline $\begin{array}{l}\% \text { who had } \\
\text { transplant }\end{array}$ & 0.39 & 43.67 \\
\hline
\end{tabular}

ANZData registry: Australia, New Zealand Data registry; CKD: chronic kidney disease.

patients defaulted after less than a month on dialysis. In the light of the findings in this present study and others [15] we propose the following, for maintenance HD indications in ESRD in Nigeria: (1) confirmed ESRD as per KDIGO definition, (2) ability to sustain dialysis for a minimum of three months, (3) reliable and accessible HD centre at an acceptable distance, (4) informed consent to continue with dialysis after appropriate explanation, (5) absence of other serious comorbidities that will lead to patient's demise even before ESRD, and (6) absence of terminal diseases.

Age distribution of patients seen revealed that most of them were in their productive years-less than 60 years of age unlike what is observed in developed world $[14,16$, 17]. Table 4 shows that the peak age of presentation in developed countries is 65-74 years unlike 36-60 years noted in this present study. The implication of this to the country's economy is obvious. Similar age distribution has been documented in other studies on ESRD in Nigeria [3, 7] and in other developing countries [18]. Reasons adduced for the younger age of patients with ESRD in the developing world include high prevalence of infections/infestations especially in childhood leading to CGN which is the commonest cause of ESRD in this part of the world $[19,20]$. In addition these patients present relatively late to the nephrologist when 


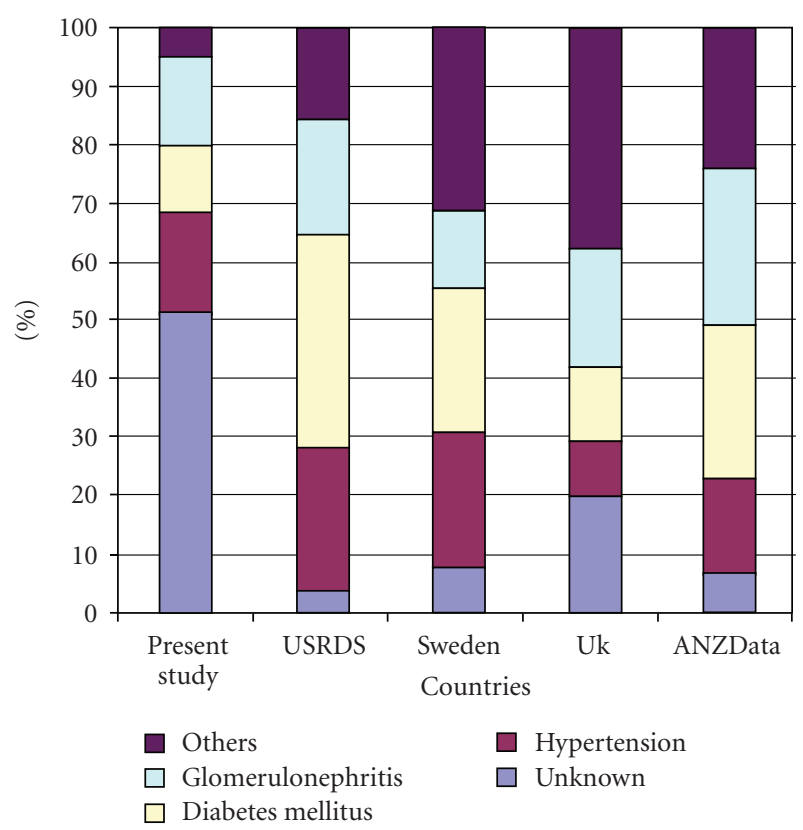

Figure 1: Comparison of causes of chronic kidney disease in different regions (present study in Nigeria, United States [17], Europe [25], and Australia [14]).

the disease is advanced. Inadequate investigation and treatment/control of such causes of ESRD as hypertension and diabetes also contribute. Hypertensive nephrosclerosis is the 2nd commonest cause of ESRD in our environment $[19,20]$. Hypertension runs a more aggressive cause in blacks and also hypertensive nephrosclerosis is more common in blacks [21]. Diabetic nephropathy is also commoner in blacks and runs a more aggressive course and often occurs at a young age than in Caucasians [22]. The brunt of HIV pandemic is borne by Sub-saharan Africa and many of such patients develop ESRD from HIVAN and other glomerulopathies [23]. Use of nephrotoxic agents including traditional/native medication, mercury-containing soaps/skin lightening creams, is rampant in the study community [24]. Awareness of deleterious effect of these agents is low in these areas. However, because of late presentation of our patients, the full impact of ESRD from use of nephrotoxic agents is not quite obvious, as earlier and mild forms of the disease do not present to hospitals. Chronic haemodialysis became available in Nigeria in late 1981, and by 2003 there were 27 dialysis units in the country. By 2006, with a population of the nation estimated at about 130 million there were 84 nephrologists and 56 dialysis units [13]. These units are mainly located in urban areas and are run with refurbished poorly maintained machines. In SouthEast Nigeria (the study area), there were only two centres that offered dialysis in 2003 but currently there are 7 dialysis centres: 2 government owned and 5 privately owned centres. Of the seven, only one is in a rural area.

In 1998 kidney transplant service was started in a private clinic in Lagos but was soon followed by three centres in Government owned Teaching Hospitals. Presently only the privately owned centre is fully functional.
ESRD disease cases in this present study accounted for about $8 \%$ of patients admitted into the medical wards. This falls within the range of $2-12 \%$ that has been reported in the past in Nigeria $[3,4]$. It is important to note, however, that renal cases accounted for $23 \%$ of all new medical cases that presented to the outpatient department. In majority of the patients the primary cause of kidney disease was not known (Table 2). But for those whom the primary kidney disease was known, hypertension was most prevalent followed by chronic glomerulonephritis and diabetes mellitus. It is probable that both chronic glomerulonephritis and hypertension could account for a good number of the cases in which the primary kidney disease was not known. Several studies in Nigeria have documented chronic glomerulonephritis and hypertension as the commonest causes of ESRD [3, 7]. Similarly, in other developing countries glomerulonephritis is still the prevalent cause of ESRD [18]. This is unlike what is obtained in the developed countries where diabetes mellitus seems to be most prevalent $[7,17,25]$ (Figure 1), reflecting the high prevalence of infectious diseases in developing countries.

Most of our patients could not cope with the financial burden of renal replacement therapy resulting in high rate of treatment withdrawal. In India, treatment withdrawal was reported as the cause of death in $70 \%$ of patients [18]. It is rather an unfortunate situation but it is the REALITY of what is obtained in developing countries and in most SubSaharan African countries. Only a small fraction of patients with ESRD in this study had renal transplant (0.39\%).

In conclusion this study highlights the poor outcome and grim outlook for patients with ESRD in Nigeria and indeed most Sub-Saharan African countries. It also brings to the fore the young age of patients with ESRD, the late presentation, and high rate of treatment withdrawal of patients. It therefore underscores the pressing need for aggressive and comprehensive strategies for early detection and treatment of causes of CKD at the primordial and primary prevention levels, as advocated by International Society of Nephrology, to reduce the impact of CKD in the society. The institution of such preventive measures for early diagnosis and adequate treatment of ESRD causes as prompt and early treatment of infections and infestations, tight glycaemic control $(\mathrm{HbA1c}<7 \%)$ for patients with diabetes mellitus and adequate blood pressure control to $<130 / 80$ should be reinforced. Other measures such as education of the policy makers, other medical practitioners, and the general public would help raise awareness. Furthermore, because most patients who start maintenance haemodialysis as form of RRT in Nigeria are unable to sustain it, strict patient selection is advised and the criteria for initiating maintenance haemodialysis in resource poor countries have been proposed in this article.

\section{References}

[1] World Health Organisation, "Global burden of disease," March 2006, http://www3.who.int/whosis/menu.cfm?path= evidence. 
[2] M.-A. Gall, K. Borch-Johnsen, P. Hougaard, F. S. Nielsen, and H.-H. Parving, "Albuminuria and poor glycemic control predict mortality in NIDDM," Diabetes, vol. 44, no. 11, pp. 1303-1309, 1995.

[3] W. Akinsola, W. O. Odesanmi, J. O. Ogunniyi, and G. O. A. Ladipo, "Diseases causing chronic renal failure in Nigeriansa prospective study of 100 cases," African Journal of Medicine and Medical Sciences, vol. 18, no. 2, pp. 131-137, 1989.

[4] A. Adetuyibi, J. B. Akisanya, and B. O. Onadeko, "Analysis of the causes of death on the medical wards of the University College Hospital, Ibadan over a 14 year period (1960-1973)," Transactions of the Royal Society of Tropical Medicine and Hygiene, vol. 70, no. 5-6, pp. 466-473, 1976.

[5] A. S. Levey, J. Coresh, K. Bolton, et al., "K/DOQI clinical practice guidelines for chronic kidney disease: evaluation, classification, and stratification," American Journal of Kidney Diseases, vol. 39, no. 2, supplement 1, pp. S1-S246, 2002.

[6] A. K. Bello, E. Nwankwo, and A. M. El Nahas, "Prevention of chronic kidney disease: a global challenge," Kidney International, Supplement, vol. 68, no. 98, pp. S11-S17, 2005.

[7] L. I. Ojogwu and C. O. Anah, "Renal failure and hypertension in tropical Africa-a pre-dialysis experience from Nigeria," East African Medical Journal, vol. 60, no. 7, pp. 478-484, 1983.

[8] S. Kadiri, A. Arije, and B. L. Salako, "Traditional herbal preparations and acute renal failure in South West Nigeria," Tropical Doctor, vol. 29, no. 4, pp. 244-246, 1999.

[9] C. K. Ijoma, I. I. Ulasi, and A. O. Kalu, "Cost implications of treatment of end-stage renal disease in Nigeria," Journal of College of Medicine, vol. 3, no. 2, pp. 95-96, 1998.

[10] "CIA-The World Factbook-Nigeria," May 2005, https:// www.cia.gov/library/publications/the-world-factbook/geos/ ng.html.

[11] WHO, World Health Report 2002 Reducing Risks, Promoting Healthy Life, World Health Organisation, Geneva, Switzerland, 2002.

[12] S. G. Wairaga, "End-stage renal disease in Africaconservative treatment," The New African Journal of Medicine, vol. 2, no. 9, 1998.

[13] S. Naicker, "End-stage renal disease in sub-Saharan Africa," Ethnicity \& Disease, vol. 16, no. 2, supplement 2, pp. S2-5S2-9, 2009.

[14] L. Excell and S. McDonald, "Method and location of dialysis," in ANZDATA Registry Report, L. Excell and S. McDonald, Eds., pp. 26-33, Australia and New Zealand Dialysis and Transplant Registry, Adelaide, Australia, 2004.

[15] A. Arije, S. Kadiri, and O. O. Akinkugbe, "The viability of hemodialysis as a treatment option for renal failure in a developing economy," African Journal of Medicine and Medical Sciences, vol. 29, no. 3-4, pp. 311-314, 2000.

[16] P. Jungers, G. Choukroun, C. Robino, et al., "Epidemiology of end-stage renal disease in the Ile-de-France area: a prospective study in 1998," Nephrology Dialysis Transplantation, vol. 15, no. 12 , pp. 2000-2006, 2000.

[17] U.S. Renal Data System and USRDS 2005 Annual Data Report, Atlas of End-Stage Renal Disease in the United States, National Institutes of Health, National Institute of Diabetes and Digestive and Kidney Diseases, Bethesda, Md, USA, 2005.

[18] R. S. Barsoum, "Overview: end-stage renal disease in the developing world," Artificial Organs, vol. 26, no. 9, pp. 737746, 2002.

[19] S. Naicker, "End-stage renal disease in sub-Saharan and South Africa," Kidney International, Supplement, vol. 63, no. 83, pp. S119-S122, 2003.
[20] C. O. Alebiosu, O. O. Ayodele, A. Abbas, and I. A. Olutoyin, "Chronic renal failure at the Olabisi Onabanjo university teaching hospital, Sagamu, Nigeria," African Health Sciences, vol. 6, no. 3, pp. 132-138, 2006.

[21] C. R. Gibbs, D. G. Beevers, and G. Y. H. Lip, "The management of hypertensive disease in Black patients," QJM, vol. 92, no. 4, pp. 187-192, 1999.

[22] B. A. Young, W. J. Katon, M. Von Korff, et al., "Racial and ethnic differences in microalbuminuria prevalence in a diabetes population: the pathways study," Journal of the American Society of Nephrology, vol. 16, no. 1, pp. 219-228, 2005.

[23] S. J. Allison, "The renal complications of HIV," Nature Reviews Nephrology, vol. 5, no. 10, p. 545, 2009.

[24] I. I. Ulasi, C. K. Ijoma, and O. A. Kalu, "Aetiological relationship between nephrotic syndrome and mercury containing skin lightening creams and medicated soaps," Nigerian Medical Journal, vol. 46, no. 2, pp. 29-32, 2005.

[25] ERA-EDTA Registry, ERA-EDTA Registry 2003 Annual Report, Academic Medical Center, Amsterdam, The Netherlands, 2005. 


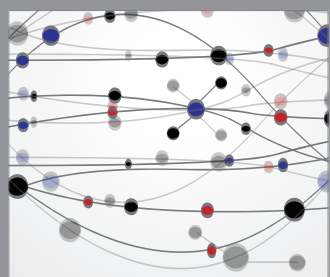

The Scientific World Journal
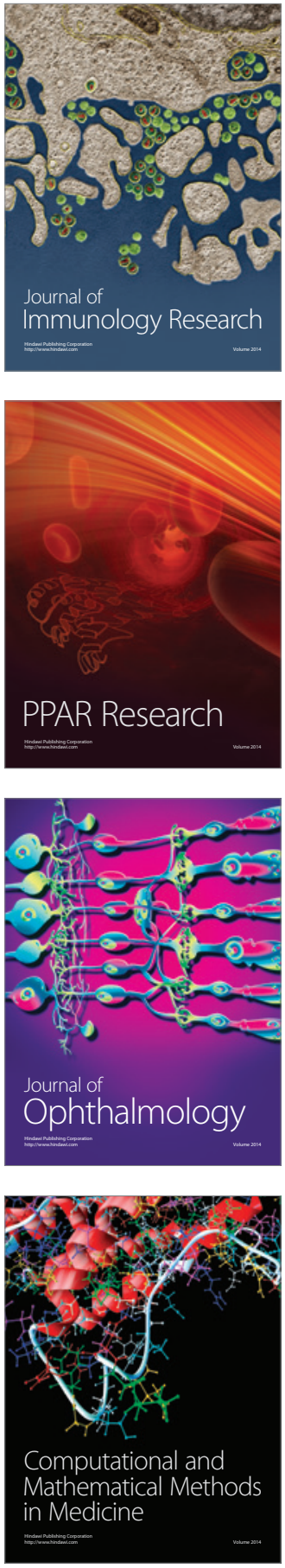

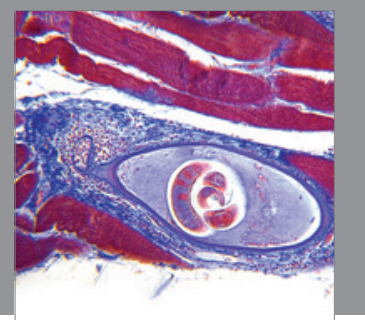

Gastroenterology

Research and Practice
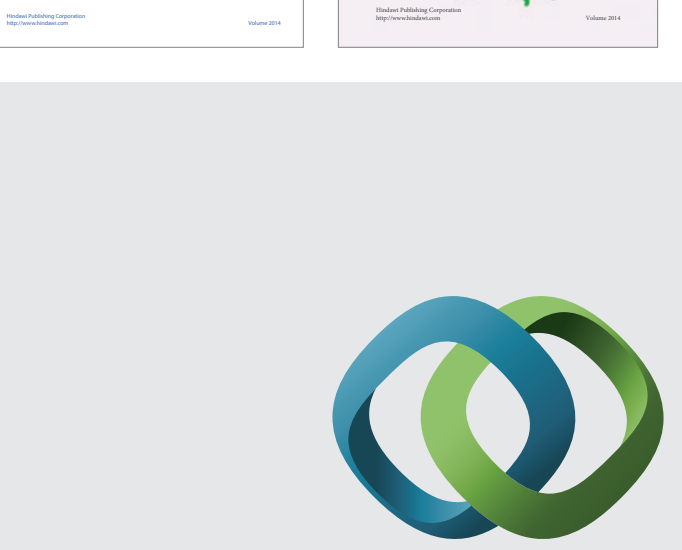

\section{Hindawi}

Submit your manuscripts at

http://www.hindawi.com
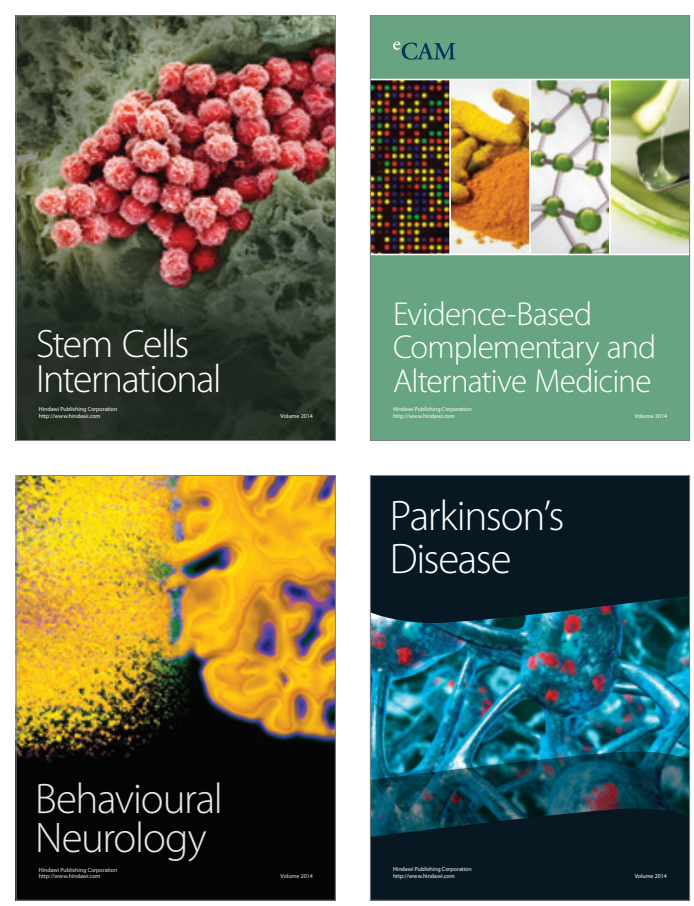

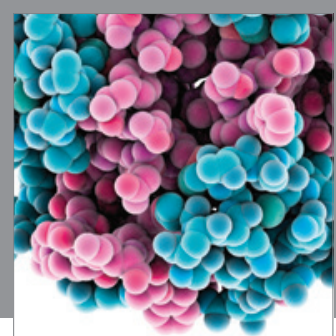

Journal of
Diabetes Research

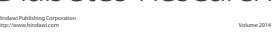

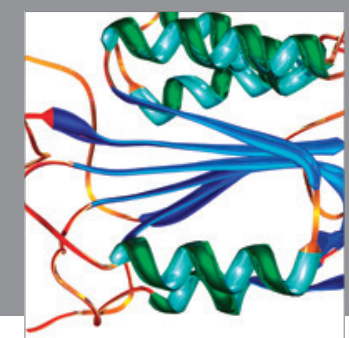

Disease Markers
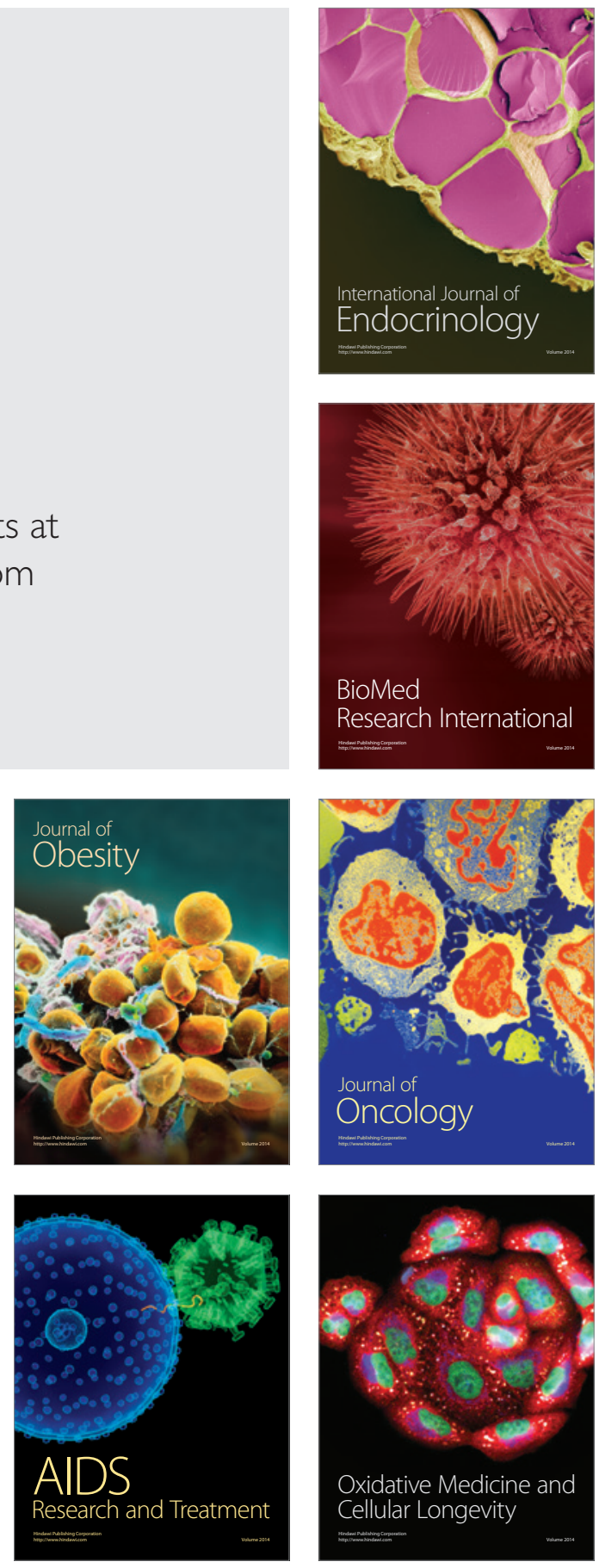